\title{
Age and Social Disparities in the Use of Telemedicine During the COVID-19 Pandemic in Japan: Cross-sectional Study
}

Atsushi Miyawaki ${ }^{1}, \mathrm{MD}, \mathrm{PhD}$; Takahiro Tabuchi ${ }^{2}, \mathrm{MD}, \mathrm{PhD}$; Michael K Ong ${ }^{3,4,5}$, MD, PhD; Yusuke Tsugawa ${ }^{3,4}$, $\mathrm{MPH}, \mathrm{MD}, \mathrm{PhD}$

\footnotetext{
${ }^{1}$ Department of Public Health, Graduate School of Medicine, The University of Tokyo, Tokyo, Japan

${ }^{2}$ Cancer Control Center, Osaka International Cancer Institute, Osaka, Japan

${ }^{3}$ Division of General Internal Medicine and Health Services Research, UCLA David Geffen School of Medicine, Los Angeles, CA, United States

${ }^{4}$ Department of Health Policy and Management, UCLA Fielding School of Public Health, Los Angeles, CA, United States

${ }^{5}$ VA Center for the Study of Healthcare Innovation, Implementation and Policy, Los Angeles, CA, United States
}

\author{
Corresponding Author: \\ Atsushi Miyawaki, MD, PhD \\ Department of Public Health \\ Graduate School of Medicine \\ The University of Tokyo \\ 7-3-1 Hongo, Bunkyo-ku \\ Tokyo, 1130033 \\ Japan \\ Phone: 81358413494 \\ Email: amiyawaki-tky@umin.ac.jp
}

\begin{abstract}
Background: The use of telemedicine outpatient visits has increased dramatically during the COVID-19 pandemic in many countries. Although disparities in access to telemedicine by age and socioeconomic status (SES) have been well-documented, evidence is limited as to how these disparities changed during the COVID-19 pandemic. Moreover, the equity of patient access to telemedicine has been scarcely reported in Japan, despite the huge potential for telemedicine expansion.

Objective: We aimed to investigate changes due to age and SES disparities in telemedicine use during the COVID-19 pandemic in Japan.

Methods: Using data from a large internet survey conducted between August 25 and September 30, 2020, in Japan, we examined the associations of participant age and SES (educational attainment, urbanicity of residence, and income level) with their telemedicine use in the following two time periods during the pandemic: April 2020 and August-September 2020.

Results: Of the 24,526 participants aged 18 to 79 years $(50.8 \%$ [n=12,446] women), the proportion of individuals who reported using telemedicine increased from 2.0\% $(n=497)$ in April 2020 to 4.7\% $(n=1159)$ in August-September 2020. After adjusting for potential confounders, younger individuals were more likely to use telemedicine than older individuals in April 2020. Although this pattern persisted in August-September 2020, we also observed a substantial increase in telemedicine use among individuals aged 70 to 79 years (adjusted rates, $0.2 \%$ in April 2020 vs 3.8\% in August-September 2020; $P<.001$ after multiple comparisons). We found disparities in telemedicine use by SES in August-September 2020 that did not exist in April 2020. In August-September 2020, individuals with a university degree were more likely to use telemedicine than those with a high school diploma or less (adjusted rates, $6.6 \%$ vs $3.5 \% ; P<.001$ ). Individuals living in urban areas exhibited higher rates of telemedicine use than those living in rural areas only in August-September 2020 (adjusted rates, $5.2 \%$ vs $3.8 \% ; P<.001$ ). Disparities in telemedicine use by income level were not observed in either time period.

Conclusions: In general, younger individuals increased their use of telemedicine compared to older individuals during the pandemic, although individuals in their 70s also increased their use of telemedicine. Disparities in telemedicine use by educational attainment and urbanicity of residence widened during the COVID-19 pandemic.
\end{abstract}

(J Med Internet Res 2021;23(7):e27982) doi: 10.2196/27982

\section{KEYWORDS}

telemedicine; telehealth; disparity; access to care; COVID-19; Japan 


\section{Introduction}

The COVID-19 pandemic has led to a global public health crisis. More than 81 million cases have been reported worldwide as of the end of December 2020, with 1.8 million deaths from COVID-19 infection [1]. This pandemic has disrupted routine health services across countries, with in-person outpatient visits drastically decreasing in the United States [2,3] and Japan [4]. Telemedicine visits are partially replacing this decline in in-person visits $[3,5]$, and they allow for medical care at a safe social distance in many countries [6]. Changes in the regulations related to the use of telemedicine, including higher reimbursement rates and less restrictive security requirements (eg, allowing non-Health Insurance Portability and Accountability Act-compliant modalities such as Facetime and Skype), facilitated increases in telemedicine usage [6,7].

Telemedicine has the potential to increase access to care for historically underserved populations who experience distance and transportation barriers to the more traditional face-to-face method of providing medical care [8]. Evidence suggests that telemedicine is effective for several types of medical interventions, including smoking cessation [9], psychiatry care [10,11], and management of chronic diseases, such as diabetes, heart disease, and chronic obstructive pulmonary disease $[12,13]$. Telemedicine can improve health outcomes even among older adults who face additional hurdles when using telemedicine due to sensory barriers and multiple comorbidities [14]. However, there have been concerns that the diffusion of telemedicine technology may have exacerbated social inequality in access to new health care technologies [15]. Racial/ethnic minorities, rural residents, and those with lower educational attainment have relatively limited access to information and communications technologies (ICTs) [16,17], and thus, they are less likely to take advantage of telemedicine. Older adults are also less prepared to use telemedicine than younger adults because of disabilities in hearing and speaking or inexperience with technology $[16,18]$.

Disparities in telemedicine access by age and socioeconomic status (SES) have been well-documented during the COVID-19 pandemic. A study conducted at four clinics in San Francisco reported that the proportion of primary care visits with minority patients aged $\geq 65$ years decreased after telemedicine implementation [19]. Other studies conducted in the United States have found that telemedicine during COVID-19 was concentrated among younger individuals living in urban areas with higher SES [20-23]. Yet, these findings show disparities only at one point in the COVID-19 pandemic, and evidence is limited as to how disparities in telemedicine use by age and SES changed as the need for telemedicine persisted during the COVID-19 pandemic.

Moreover, there is limited research on the sociodemographic patterns in telemedicine use outside the United States. Japan has universal health coverage through the social insurance scheme and is one of the countries with the highest life expectancy in the world [24]. Japan has a lower number of telemedicine users compared to the United States, Canada, and European countries [25]. Recently, mainly due to the impact of the COVID-19 pandemic, policymakers in Japan have been promoting the use of telemedicine. For example, the Japanese government approved the insurance coverage of telemedicine visits in 2018, and further promoted the use of telemedicine during the COVID-19 pandemic. Although the overall use of telemedicine has increased during the COVID-19 pandemic, given that it requires patients to be familiar with health care ICTs, it is possible that it has increased disparity gaps in access to and use of telemedicine between certain subpopulations (eg, old vs young populations). However, the equity of patient access to telemedicine has not been well-characterized in Japan.

To bridge this knowledge gap, we used data from a large internet survey conducted in Japan to examine how disparities in telemedicine use by age and SES may have changed during two time periods following the declaration of the pandemic: April 2020 and August-September 2020. According to the trend in confirmed COVID-19 cases reported in Japan, April 2020 corresponded to the early stage of the first wave of the COVID-19 epidemic (under the state of emergency), and August-September 2020 was during the second wave [1]. The aim of this study was to elucidate how disparities in telemedicine use by age and SES have changed during the pandemic.

\section{Methods}

\section{Study Design, Setting, and Data Sources}

We analyzed data from the Japan "COVID-19 and Society" Internet Survey (JACSIS) study [26], a cross-sectional, web-based, self-reported questionnaire survey administered by a major nationwide internet research agency with 2.2 million qualified panelists [27-29]. Selected individuals aged 15 to 79 years $(n=224,389)$ were included in the JACSIS study using stratified random sampling based on gender, age, and prefecture category to represent the distribution of the general population in Japan in 2019 [30,31]. Individuals who agreed to participate in the survey accessed the designated website and responded to questionnaires asking about a wide range of socioeconomic, lifestyle, and health measures in the context of the COVID-19 pandemic. Questionnaires were distributed from August 25, 2020, until September 30, 2020 (hereafter, "August-September 2020 "), when the predetermined target number of participants for each gender, age, and prefecture category was met, with an overall response rate of $12.5 \%(28,000 / 224,389)$. For this study, we used a subsample of adults aged 18 to 79 years $(n=27,641)$. We sequentially excluded 2477 individuals showing unnatural or inconsistent responses using the algorithm we developed and 638 individuals whose zip code information was missing. This study was approved by the University of Tokyo (number 2020337NI).

\section{Exposure Variables}

The primary exposure variable was participant age. The secondary exposure variables were SES measures of educational attainment, urbanicity of residence, and household income level. Age was categorized into the following six groups: 18-29 (reference), 30-39, 40-49, 50-59, 60-69, and 70-79 years. Educational attainment was categorized into the following three groups: those who had a university degree or higher (reference; corresponding to the International Standard Classification of 
Education [ISCED] [32] level 6-8), a college degree (ISCED level 5; colleges included junior, community, and vocational colleges), and a high school diploma or lower (ISCED level 0-4). Urbanicity of residence was dichotomized (urban [reference] vs rural). An urban area was defined as a densely inhabited district, which was determined according to the information from the 2015 Census of Japan linked to the seven-digit zip codes reported by the participants [33]; rural area was defined as a nonurban area. Income level was based on self-reported household income and categorized into four groups using the tertiles of household equivalent income ("high" $=$ more than 4.3 million JPY [reference] [110 JPY $\fallingdotseq 1$ USD], "medium" $=2.5$ to 4.3 million JPY, or "low" = less than 2.5 million JPY) and an indicator for those who refused to respond to this question.

\section{Outcome Variables}

Our outcome of interest was whether the participant used telemedicine, defined as the examination, diagnosis, and treatment of patients by physicians via information and communication devices that contain real-time visual and auditory information (according to the Ministry of Health, Labour, and Welfare of Japan) [34]. Telemedicine use was measured at the following two different time points during the COVID-19 pandemic in 2020: (1) April and (2) August-September (at the time of the survey). We asked the participants the following question: "Have you ever used telemedicine as a patient?" Participants were to select from one of the following three options: (1) "I have used it before April 2020," (2) "I used it for the first time after April 2020," and (3) "Never." We regarded the participants who chose option 1 as using telemedicine as of April and those who chose option 1 or 2 as using telemedicine as of August-September. We defined the use of telemedicine as those individuals who ever used telemedicine, rather than using the frequency of telemedicine use as the outcome variable, because only survey participants with health issues that require medical attention actually use telemedicine (even those individuals with access to telemedicine would not use telemedicine if they had no health issue during the study period). Moreover, the frequency of telemedicine was affected by not only patients' access to telemedicine, but also several other factors including the severity of illness of patients and the physicians' practice patterns (some physicians may see patients more often than others). A similar approach has been used in prior studies $[35,36]$.

\section{Adjustment Variables}

We adjusted for the participants' sociodemographic and health-related characteristics. The sociodemographic characteristics included employment status (employer, self-employed, employee, and unemployed), marital status (married, never married, widowed, and separated), and household size (number of household members: 1, 2, 3, 4, and $5+)$. Health-related characteristics included smoking status (never, ever, and current smokers), self-rated health (excellent/good vs moderate/bad/very bad), walking disability (whether the person is experiencing difficulties in walking), and dummy variables for each of nine comorbidities (overweight $\left[\mathrm{BMI} \geq 25 \mathrm{~kg} / \mathrm{m}^{2}\right]$ and self-reported presence of eight conditions including hypertension, diabetes, asthma, coronary disease, stroke, chronic obstructive pulmonary disease, cancer, and psychological disorder). BMI was calculated by dividing self-reported body weight $(\mathrm{kg})$ by self-reported body height squared $\left(\mathrm{m}^{2}\right)$.

\section{Statistical Analysis}

First, we described the sociodemographic and health-related characteristics of the participants. To account for the possibility that those who participated and responded to the internet-based survey might differ from the general population, we applied an inverse probability weighting (IPW) approach throughout the analyses [37]. The details of the calculation for IPW are described in Multimedia Appendix 1.

Second, we examined the association between age and rates of telemedicine use in April 2020 or August-September 2020. For each outcome, we constructed a weighted multivariable logistic regression model (IPW described above) that controlled for potential confounders (the other exposures [ie, educational attainment, urbanicity of residence, and income level] and sociodemographic/health-related characteristics). Standard errors were clustered at the prefecture level to account for the potential correlation of participants within the same prefecture. Japan consists of 47 prefectures, which are the country's first jurisdiction and administrative division levels. To calculate adjusted rates of telemedicine use, we employed marginal standardization (also known as predictive margins or margins of response). For each participant, we calculated predicted probabilities of telemedicine use with the exposure fixed at each category and then averaged over the distribution of the adjustment variables in our sample.

Third, to examine the adjusted change in telemedicine use from April 2020 to August-September 2020, we calculated the difference in the adjusted rates of telemedicine use between these two time points for each age group.

Finally, we tested if the adjusted changes in telemedicine use from April 2020 to August-September 2020 varied across age, by calculating the difference in differences. We also used a similar approach to examine the adjusted rates of telemedicine use and their changes by each SES aspect (educational attainment, urbanicity of residence, and income level).

We used the Benjamini-Hochberg method to account for the multiple comparisons across $15(6+3+2+4)$ exposure categories $(11[5+2+1+3]$ categories for the difference in the adjusted differences), and reported both unadjusted and adjusted $P$ values (adjusted $P$ values <.05 were considered as statistically significant) [38,39]. All analyses were conducted using Stata version 15 (StataCorp LLC).

\section{Secondary Analyses}

We conducted sensitivity analyses. First, we additionally adjusted for indicator variables for each prefecture (prefecture fixed effects) to effectively compare individuals living in the same prefecture. Second, we additionally adjusted for four categorical variables representing availability of ICTs, including internet access at home and ownership of personal computers, smartphones, and tablet computers, to test whether online access 
could explain the observed disparities in the rate of telemedicine use by age and SES.

\section{Results}

\section{Characteristics of the Participants}

A total of 24,526 participants $(88.7 \%$ of the total adult subsample) were included in our analyses. There were 12,446 women (50.8\%), and the mean age at the time of the survey was 50.1 (SD 16.6) years. Those who had a high school diploma or less were the most numerous, accounting for half of the participants $(12,030 / 24,526,49.1 \%)$, while one-third $(7915 / 24,526,32.3 \%)$ of the participants had a university degree or higher, and less than $20 \%(4581 / 24,526,18.7 \%)$ had a college degree. Approximately $60 \%(14,666 / 24,526,59.8 \%)$ of the participants lived in urban areas (Table 1). 
Table 1. Characteristics of the participants.

\begin{tabular}{|c|c|}
\hline Characteristics & Value $(\mathrm{N}=24,526)$ \\
\hline Female, n (\%) & $12,446(50.8 \%)$ \\
\hline Age (years), mean (SD) & $50.1(16.6)$ \\
\hline \multicolumn{2}{|l|}{ Educational attainment, n (\%) } \\
\hline University degree or higher & $7915(32.3 \%)$ \\
\hline College degree $^{\mathrm{a}}$ & $4581(18.7 \%)$ \\
\hline High school diploma or lower & $12,030(49.1 \%)$ \\
\hline \multicolumn{2}{|l|}{ Urbanicity of residence, $n(\%)$} \\
\hline Urban & $14,666(59.8 \%)$ \\
\hline Rural & $9560(40.2 \%)$ \\
\hline \multicolumn{2}{|l|}{ Income level, n (\%) } \\
\hline High & $5458(22.3 \%)$ \\
\hline Medium & $6814(27.8 \%)$ \\
\hline Low & $7151(29.2 \%)$ \\
\hline Not answered & $5103(20.8 \%)$ \\
\hline \multicolumn{2}{|l|}{ Employment status, n (\%) } \\
\hline Employer & $1011(4.1 \%)$ \\
\hline Self-employed & $1892(7.7 \%)$ \\
\hline Employee & $12,623(51.5 \%)$ \\
\hline Unemployed & $9000(36.7 \%)$ \\
\hline \multicolumn{2}{|l|}{ Marital status, n (\%) } \\
\hline Married & $16,102(65.7 \%)$ \\
\hline Never married & $5413(22.1 \%)$ \\
\hline Widowed & $1606(6.6 \%)$ \\
\hline Separated & $1403(5.7 \%)$ \\
\hline \multicolumn{2}{|l|}{ Household size, n (\%) } \\
\hline 1 & $4152(16.9 \%)$ \\
\hline 2 & $8386(34.2 \%)$ \\
\hline 3 & $5547(22.6 \%)$ \\
\hline 4 & $4124(16.8 \%)$ \\
\hline$\geq 5$ & $2317(9.5 \%)$ \\
\hline \multicolumn{2}{|l|}{ Smoking status, n (\%) } \\
\hline Never & $12,186(49.7 \%)$ \\
\hline Ever & $7423(30.3 \%)$ \\
\hline Current & $4917(20.0 \%)$ \\
\hline Self-rated good health ${ }^{\mathrm{b}}, \mathrm{n}(\%)$ & $9839(40.1 \%)$ \\
\hline Walking disability, n (\%) & $3142(12.8 \%)$ \\
\hline \multicolumn{2}{|l|}{ Comorbidities, n (\%) } \\
\hline Overweight & $5202(21.2 \%)$ \\
\hline Hypertension & $5086(20.7 \%)$ \\
\hline Diabetes & $1911(7.8 \%)$ \\
\hline Asthma & $1450(5.9 \%)$ \\
\hline
\end{tabular}




\begin{tabular}{ll}
\hline Characteristics & Value $(\mathrm{N}=24,526)$ \\
\hline Coronary disease & $923(3.8 \%)$ \\
Stroke & $459(1.9 \%)$ \\
Chronic obstructive pulmonary disease & $332(1.4 \%)$ \\
Cancer & $774(3.2 \%)$ \\
Psychological disorder & $1848(7.5 \%)$ \\
\hline
\end{tabular}

${ }^{\mathrm{a} C}$ College includes junior, community, and vocational college.

${ }^{\mathrm{b}}$ Self-rated good health was defined as very good or good using the 5-point Likert scale question, which asked if self-rated health status was very good, good, moderate, bad, or very bad.

\section{Overall Trend in the Rates of Telemedicine Use}

Of the 24,526 participants aged 18 to 79 years $(50.8 \%$ $[\mathrm{n}=12,446]$ women), the proportion of individuals who reported using telemedicine increased from 2.0\% (n=497) in April 2020 to $4.7 \%(n=1159)$ in August-September 2020.

\section{Adjusted Rates of Telemedicine Use by Age}

After adjusting for potential confounders, younger individuals were more likely to use telemedicine than older individuals in April 2020 (Figure 1 and Multimedia Appendix 2). Although this pattern remained largely unchanged in August-September 2020, with participants aged 18 to 29 years exhibiting the largest increase in telemedicine use (adjusted rates, $4.3 \%$ in April vs
$10.2 \%$ in August-September; adjusted difference, +5.8 percentage points; adjusted $P<.001$ ), we also observed a substantial increase in telemedicine use among participants aged 70 to 79 years (from $0.2 \%$ to $3.8 \%$; +3.5 percentage points; $P<.001$ ) (Table 2). The increase in the adjusted rates of telemedicine use among participants aged 18 to 29 years was 3.5 percentage points larger compared to that among those aged 40 to 49 years $(P=.04), 3.9$ percentage points larger compared to that among those aged 50 to 59 years $(P=.01)$, and 4.5 percentage points larger compared to that among those aged 60 to 69 years $(P=.003)$. However, we found no evidence that the increase in the rates of telemedicine use differed between those aged 18 to 29 years and 70 to 79 years $(P=.19)$.

Figure 1. Adjusted rates of telemedicine use in April 2020 and August-September 2020 by age. Telemedicine use was defined as "ever use" of telemedicine at a given time point (April or August-September 2020). Rates of telemedicine use were adjusted for other exposures and sociodemographic/health-related characteristics. We statistically compared the adjusted rates of telemedicine by age groups (reference: age 18-29 years) in April 2020 and in August-September 2020. **Adjusted $P<.01$, ***Adjusted $P<.001$.

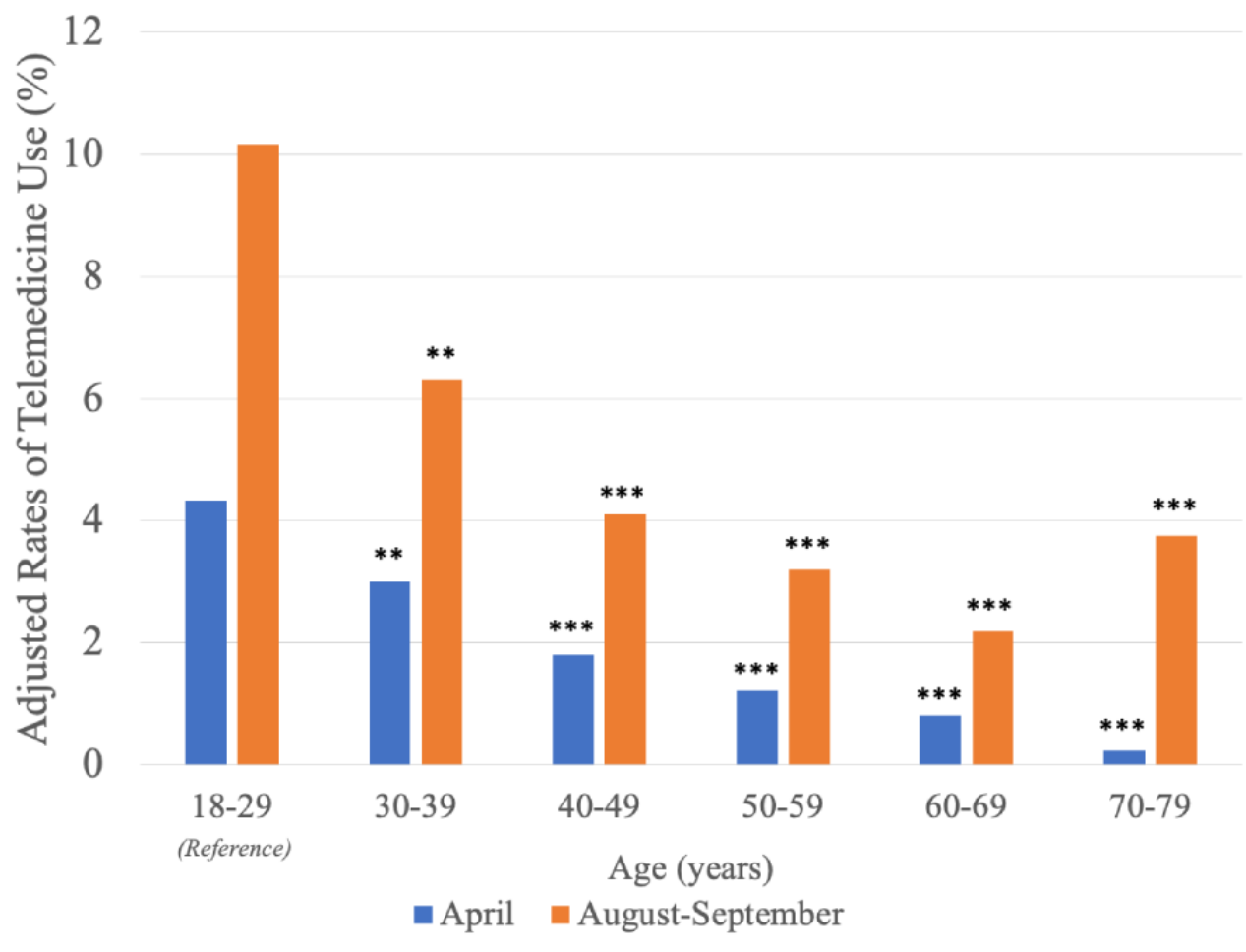


Table 2. Difference in the adjusted rates of telemedicine use between April 2020 and August-September 2020 by age.

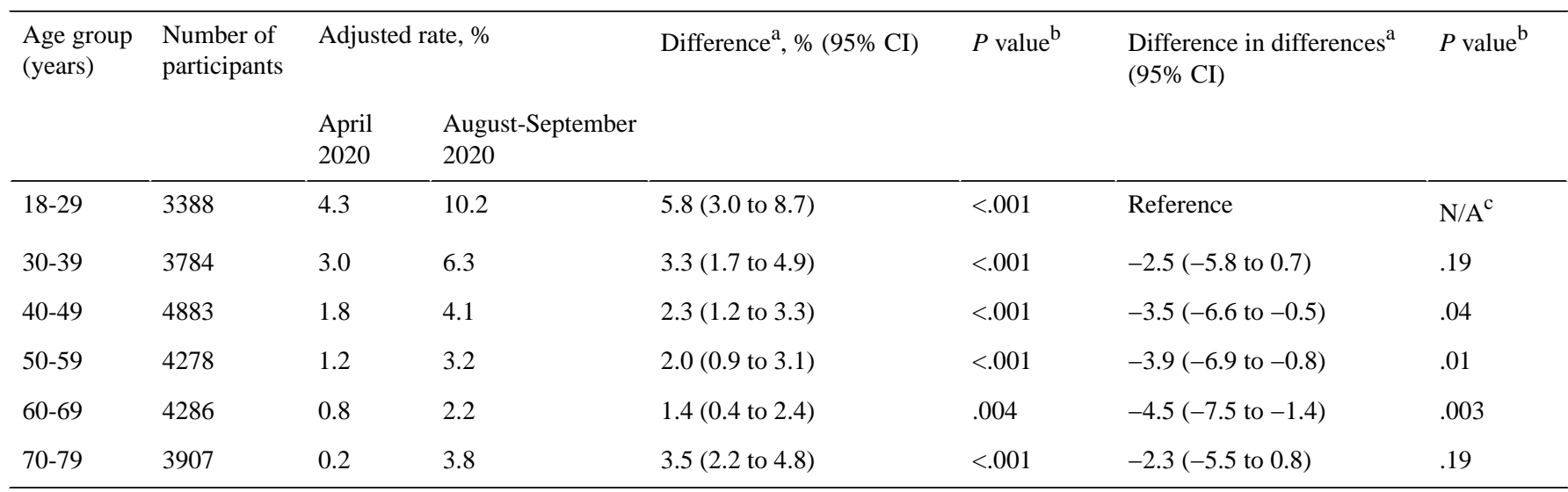

${ }^{\mathrm{a}}$ We calculated the differences in the adjusted rates of telemedicine use between April 2020 and August-September 2020 for each age group. Then, we examined how the difference in the rates of telemedicine use between the two time points varied by age (difference in differences). The analyses were weighted to account for selection in an internet survey. For each analysis, standard errors were clustered at the prefecture level.

${ }^{b}$ The $P$ values were adjusted post hoc to account for multiple comparisons with the use of the Benjamini-Hochberg method.

${ }^{\mathrm{c}} \mathrm{N} / \mathrm{A}$ : not applicable.

\section{Adjusted Rates of Telemedicine Use by SES Measures}

\section{Educational Attainment}

We found no evidence that the adjusted rates of telemedicine use differed by educational attainment in April 2020 (Figure 2). In contrast, we found disparities in telemedicine use by SES in August-September 2020. Participants with a university degree or higher were more likely to use telemedicine than those with a college degree (adjusted rates, $6.6 \%$ vs $4.0 \% ; P=.006$ ) or high school diploma or less (adjusted rates, $6.6 \%$ vs $3.5 \% ; P<.001$ ) (Multimedia Appendix 2). The increase in the adjusted rates of telemedicine use among participants with a university degree or higher was 2.2 percentage points larger compared to that among those with a college degree $(P=.01)$ and 2.7 percentage points larger compared to that among those with a high school diploma or less $(P=.003)$ (Table 3$)$. 
Figure 2. Adjusted rates of telemedicine use in April 2020 and August-September 2020 by socioeconomic status measures. Telemedicine use was defined as "ever use" of telemedicine at a given time point (April or August-September 2020). Rates of telemedicine use were adjusted for other exposures and sociodemographic/health-related characteristics. We statistically compared the adjusted rates of telemedicine by educational attainment (reference: having a university degree or more), urbanicity of residence (reference: living in urban areas), or income level (reference: high income) in April 2020 and in August-September 2020. **Adjusted $P<.01$, ***Adjusted $P<.001$.

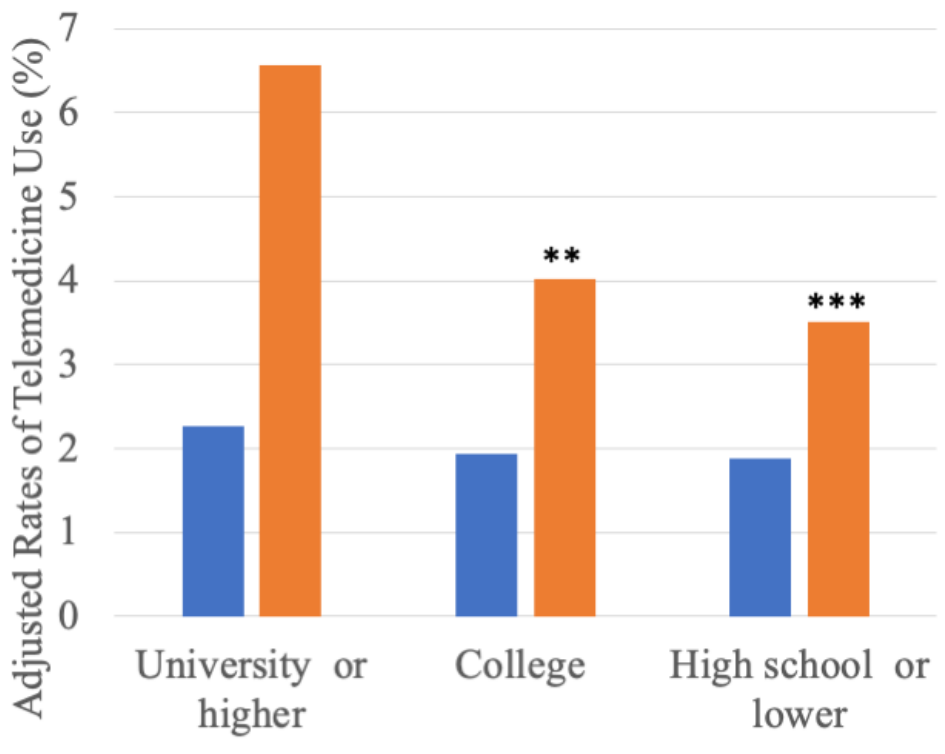

(Reference)

Educational attainment

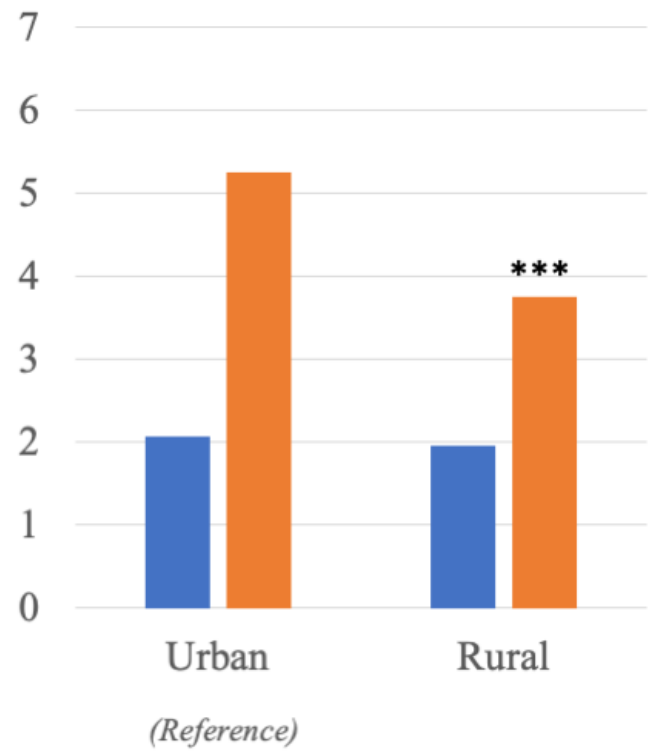

Urbanicity

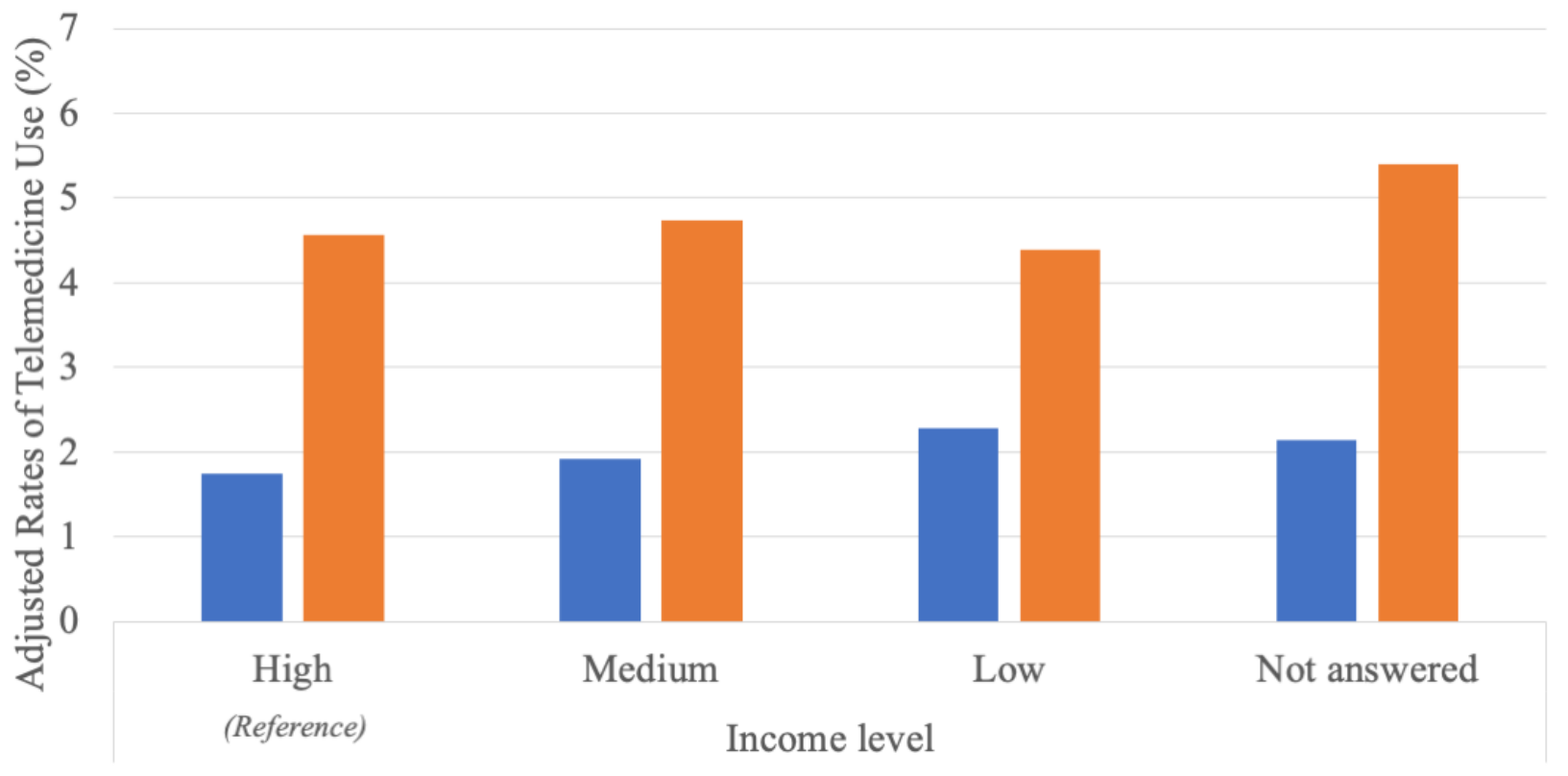

- April August-September 
Table 3. Difference in the adjusted rates of telemedicine use between April 2020 and August-September 2020 by socioeconomic status measures.

\begin{tabular}{|c|c|c|c|c|c|c|c|}
\hline \multirow[t]{2}{*}{ Measure } & \multirow{2}{*}{$\begin{array}{l}\text { Number of } \\
\text { participants }\end{array}$} & \multicolumn{2}{|c|}{ Adjusted rate, $\%$} & \multirow{2}{*}{$\begin{array}{l}\text { Difference }{ }^{\mathrm{a}} \text {, } \\
\%(95 \% \mathrm{CI})\end{array}$} & \multirow[t]{2}{*}{$P$ value $^{\mathrm{b}}$} & \multirow{2}{*}{$\begin{array}{l}\text { Difference in differences }{ }^{\mathrm{a}} \\
(95 \% \mathrm{CI})\end{array}$} & \multirow[t]{2}{*}{$P$ value $^{\mathrm{b}}$} \\
\hline & & April 2020 & $\begin{array}{l}\text { August- } \\
\text { September } \\
2020\end{array}$ & & & & \\
\hline \multicolumn{8}{|l|}{ Educational attainment } \\
\hline University or higher & 7915 & 2.3 & 6.6 & $4.3(2.7$ to 5.9$)$ & $<.001$ & Reference & $\mathrm{N} / \mathrm{A}^{\mathrm{c}}$ \\
\hline College & 4581 & 1.9 & 4.0 & $2.1(1.3$ to 2.9$)$ & $<.001$ & $-2.2(-4.0$ to -0.4$)$ & .01 \\
\hline High school or lower & 12,030 & 1.9 & 3.5 & $1.6(0.9$ to 2.4$)$ & $<.001$ & $-2.7(-4.4$ to -0.9$)$ & .003 \\
\hline \multicolumn{8}{|l|}{ Urbanicity of residence } \\
\hline Urban & 14,666 & 2.1 & 5.2 & $3.2(2.4$ to 3.9$)$ & $<.001$ & Reference & N/A \\
\hline Rural & 9860 & 2.0 & 3.8 & $1.8(1.2$ to 2.4$)$ & $<.001$ & $-1.4(-2.3$ to -0.4$)$ & .004 \\
\hline \multicolumn{8}{|l|}{ Income level } \\
\hline High & 5458 & 1.7 & 4.6 & $2.8(1.8$ to 3.8$)$ & $<.001$ & Reference & N/A \\
\hline Medium & 6814 & 1.9 & 4.7 & $2.8(1.5$ to 4.2$)$ & $<.001$ & $0(-1.6$ to 1.7$)$ & .99 \\
\hline Low & 7151 & 2.3 & 4.4 & $2.1(1.3$ to 2.9$)$ & $<.001$ & -0.7 ( -2.0 to 0.6$)$ & .34 \\
\hline Not answered & 5103 & 2.1 & 5.4 & $3.2(1.1$ to 5.4$)$ & .003 & $0.4(-2.0$ to 2.8$)$ & .79 \\
\hline
\end{tabular}

${ }^{\mathrm{a}}$ We calculated the differences in the adjusted rates of telemedicine use between April 2020 and August-September 2020 for each socioeconomic status measure (educational attainment, urbanicity of residence, or income level). Then, we examined how the difference in the rates of telemedicine use between the two time points varied by educational attainment, urbanicity of residence, or income level (difference in differences). The analyses were weighted to account for selection in an internet survey. For each analysis, standard errors were clustered at the prefecture level.

${ }^{\mathrm{b}}$ The $P$ values were adjusted post hoc to account for multiple comparisons with the use of the Benjamini-Hochberg method.

${ }^{\mathrm{c}}$ N/A: not applicable.

\section{Urbanicity of Residence}

We found no evidence that the adjusted rates of telemedicine use differed by urbanicity of residence in April 2020 (Figure 2). Participants living in urban areas exhibited higher rates of telemedicine use than those living in rural areas only in August-September 2020 (adjusted rates, $5.2 \%$ vs $3.8 \%$; $P<.001$ ) (Multimedia Appendix 2). The increase in the adjusted rates of telemedicine use among participants living in urban areas was 1.4 percentage points higher compared to that among those living in rural areas $(P=.004)$ (Table 3$)$.

\section{Income Level}

We found no evidence that the adjusted rates of telemedicine use differed by income level in April or August-September 2020 (Figure 2). We also found no evidence that the increase in the rates of telemedicine use varied by income level (Table 3).

\section{Secondary Analyses}

Our findings were qualitatively unaffected by additional adjustment for prefecture fixed effects (Multimedia Appendix 3 ). When we additionally adjusted for the variables representing the availability of ICTs, our findings of increased disparities by SES (ie, university or higher vs high school or lower and urban vs rural) were largely unaffected (Multimedia Appendix 4). However, we no longer found any evidence that the increase in the rates of telemedicine use varied between young individuals (aged 18-29 years) and middle-aged individuals (aged 40-49, 50-59, or 60-69 years), indicating that the trends of the disparities in telemedicine use by age were partly driven by differences in online access.

\section{Discussion}

\section{Principal Findings}

Using data from a large nationwide internet survey conducted in Japan, we found that younger individuals increased the use of telemedicine more than older individuals (leading to wider disparities by age) during the COVID-19 pandemic, although individuals in their 70s also increased the use of telemedicine. Disparities in telemedicine use by educational attainment and urbanicity of residence also increased during the pandemic, whereas we found no evidence that disparities by income level changed.

Younger people were already more likely to use telemedicine as of April 2020; this disparity by age further increased as of August-September 2020 among adults aged 69 years or younger. However, telemedicine use also increased among older adults aged 70 to 79 years, narrowing the gap in telemedicine use among this population. In April 2020, there was no evidence that telemedicine use varied across educational attainment and urbanicity of residence, but by August-September 2020, better educated individuals living in urban areas were more likely to use telemedicine. In contrast, we did not find significant disparities by income level in either April or August-September 2020. Taken together, these findings suggest that improved access to telemedicine during the pandemic may have penetrated 
unevenly in the population, leaving behind some socioeconomically disadvantaged populations. In contrast, the growing use of telemedicine among older adults was reassuring, indicating that this population of people, who have high health care needs but are often unfamiliar with ICTs [16], benefitted from improved access to telemedicine.

There may be several mechanisms through which the disparities in telemedicine use due to age have widened, especially among individuals aged 69 years or younger. First, younger people may have been more familiar with ICTs, and therefore, faced lower psychological or technological hurdles to initiating telemedicine usage when access to it improved in response to the COVID-19 pandemic in Japan [16]. This explanation is supported by our findings showing no evidence of disparities in telemedicine use due to age once we adjusted for the indicators of ICT availability. Second, the health care needs of young patients may be milder than those of older patients, making young patients more suited to the use of telemedicine. For example, young patients may have fewer comorbidities and seek care for milder conditions compared to middle-aged or older adults. Young patients also may be less likely to need blood tests or diagnostic imaging, which require patients to physically visit a health care facility [40,41]. Finally, younger individuals may be less likely to have disabilities and sensory barriers that could be hurdles to telemedicine use [14].

We also found that individuals aged 70 to 79 years experienced a large increase in telemedicine use. Given that these older adults are in the highest-risk age group for COVID-19 infection (most likely to experience severe life-threatening conditions when infected) [42], they might be incentivized to use telemedicine to avoid visiting health care facilities, which might lead to COVID-19 infection.

The limited increase in telemedicine use for individuals with lower academic attainment may be due to their lower digital literacy, limited access to ICTs, and less flexible work schedules [43], all of which could be barriers to using telemedicine [16]. The limited penetration of telemedicine use in rural areas may be explained by inadequate internet access in rural areas [16] and the fact that there were fewer medical institutions offering telemedicine in rural areas [44]. Given that the number of COVID-19 infections was generally higher in urban areas compared with rural areas, another potential explanation for the relative expansion in telemedicine use in urban areas may be that patients living in urban areas were more incentivized to avoid face-to-face encounters. However, we found that the inclusion of prefecture fixed effects (effectively comparing urban vs rural areas within the same prefecture) did not qualitatively change our results, indicating that this does not fully explain the disparities in telemedicine use between residents of urban and rural areas. It was reassuring that we found no substantial disparities in access to telemedicine by income level throughout the study period. Our findings may indicate that, at least in Japan, financial barriers have minimally influenced the disparities in telemedicine use.

\section{Comparison With Prior Work}

Our findings add to the body of work investigating the impact of age and SES on telemedicine use during the COVID-19 pandemic. Studies that were conducted prior to the expansion of telemedicine use in response to the COVID-19 pandemic have reported that younger patients are more likely to use telemedicine, whereas these studies showed mixed results regarding the disparities by area income level and urbanicity of residence. Studies that were conducted after the COVID-19 pandemic found that telemedicine use overall $[41,45,46]$ and for geriatric care [21], primary care [19,22,47], or otolaryngological care [23] was concentrated among younger individuals living in urban high-income areas. Yet, the timeframe used in these studies represented only one early point in the COVID-19 pandemic, and the studies did not focus on the change over time of age and social disparities in telemedicine use. These previous studies used area income level as an indicator of income level, as opposed to individual income level used in our research. The inconsistent results for income level may partly be attributable to this difference. More importantly, to our knowledge, our study is the first to show that telemedicine use increased substantially among individuals aged 70 years or older, reducing telemedicine disparities among the population at the highest risk for COVID-19 infection.

\section{Limitations}

Our study has some limitations. First, as with any observational study, we could not fully account for unmeasured confounders. Our study also was unable to identify the exact mechanisms of the association between age or SES and the increase in the rates of telemedicine use. Second, due to a limitation in our data, we were unable to identify whether telemedicine use represented telephone visits or virtual visits. Third, there is potential for recall bias; younger individuals with higher SES might be more likely to recall and report telemedicine use. Fourth, we could not identify the clinical conditions for which patients received care via telemedicine. The reports submitted to the government by medical institutions offering telemedicine indicated that the most common conditions for which patients used telemedicine between July and September 2020 were acute relatively mild conditions, such as upper respiratory tract infection, fever, bronchitis, and rhinitis [44]. However, evidence suggests that telemedicine is suitable for psychiatric care [10,11] and management of chronic conditions [12,13]. This gap may be due to patients avoiding clinic visits with signs of infection and shifting to telemedicine, or the Japanese authorities' restriction on the prescription of psychiatric drugs in telemedicine [44]. The patterns of telemedicine use by age and SES may change as the profiles of conditions treated via telemedicine increase in the future. Finally, because our study sample was collected through an internet-based survey, our findings may not be generalizable to a population with limited access to and/or literacy of the internet. However, we used weighted analyses to minimize the difference in demographics, SES, and health-related characteristics between respondents of the current internet survey and the nationally representative survey, thus approximating our estimates to national estimates.

\section{Conclusions}

Using a large-scale nationwide internet survey in Japan, we found that younger individuals were generally more likely to increase telemedicine use than older individuals during the 
pandemic, although individuals in their 70s exceptionally gained access to telemedicine. Disparities in telemedicine use by educational attainment and urbanicity of residence increased during the COVID-19 pandemic. These findings indicate that the current telemedicine expansion may be leaving a portion of the socioeconomically disadvantaged population behind, and suggest further need for policy efforts to achieve equal access to health care.

\section{Acknowledgments}

Data collection and statistical analyses in this work were funded by the Japan Society for the Promotion of Science (JSPS) KAKENHI Grants (18H03062 to TT). AM was supported by JSPS KAKENHI Grants (20K18956) and the Social Science Research Council (grant number is not applicable) for other work not related to this study. YT was supported by the National Institutes of Health (NIH)/National Institute on Minority Health and Health Disparities Grant R01MD013913 and NIH/National Institute of Aging Grant R01AG068633 for other work not related to this study. The data from the JACSIS study were collected with the support of JSPS KAKENHI Grants (grant numbers 18H03062, 17H03589, 19K10671, 19K19439, 19K10446, and 18H03107), the University of Tsukuba Research Support Program (grant number is not applicable), and Health Labour Sciences Research Grants (19FA1005). The content of this paper is solely the responsibility of the authors and does not necessarily represent the official views of the funders. The funders were not involved with the collection, management, analysis, or interpretation of the data; preparation, review, or approval of the manuscript; or the decision to submit the manuscript for publication. All authors had full access to all the data in the study and had final responsibility for the decision to submit the paper.

\section{Authors' Contributions}

AM had full access to the data in the study and takes responsibility for the accuracy and integrity of the data and its analyses. Study concept and design: All authors. Acquisition, analysis, or interpretation of data: All authors. Drafting of the manuscript: AM and YT. Critical revision of the manuscript for important intellectual content: All authors. Statistical analysis: AM, TT, and YT. Administrative, technical, or material support: YT. Study supervision: YT.

\section{Conflicts of Interest}

MKO receives royalties from UpToDate for its telemedicine section. The other authors have no conflicts to declare.

\section{Multimedia Appendix 1}

Inverse probability weighting. [DOCX File, 22 KB-Multimedia Appendix 1]

\section{Multimedia Appendix 2}

Adjusted odds ratios of telemedicine for age and socioeconomic status measures.

[DOCX File, 21 KB-Multimedia Appendix 2]

\section{Multimedia Appendix 3}

Difference in adjusted rates of telemedicine use between April 2020 and August-September 2020 by age and socioeconomic status measures, additionally adjusting for prefecture fixed effects.

[DOCX File, $21 \mathrm{~KB}-$ Multimedia Appendix 3]

\section{Multimedia Appendix 4}

Difference in adjusted rates of telemedicine use between April 2020 and August-September 2020 by age and socioeconomic status measures, additionally adjusting for availability of information and communication technologies.

[DOCX File, 22 KB-Multimedia Appendix 4]

\section{References}

1. WHO Coronavirus Disease (COVID-19) Dashboard. World Health Organization. URL: https://covid19.who.int [accessed 2021-06-01]

2. Mehrotra A, Chernew M, Linetsky D, Hatch H, Cutler D, Schneider E. The Impact of the COVID-19 Pandemic on Outpatient Care: Visits Return to Prepandemic Levels, but Not for All Providers and Patients. The Commonwealth Fund. 2020. URL: https://www.commonwealthfund.org/publications/2020/oct/impact-covid-19-pandemic-outpatient-care-visitsreturn-prepandemic-levels [accessed 2021-06-01]

3. Baum A, Kaboli PJ, Schwartz MD. Reduced In-Person and Increased Telehealth Outpatient Visits During the COVID-19 Pandemic. Ann Intern Med 2021 Jan;174(1):129-131 [FREE Full text] [doi: 10.7326/M20-3026] [Medline: $\underline{32776780]}$ 
4. Hospital Report (August 2020). Ministry of Health Labour and Welfare. 2020. URL: https://www.mhlw.go.jp/toukei/list/ 80-1.html [accessed 2020-12-31]

5. Patel SY, Mehrotra A, Huskamp HA, Uscher-Pines L, Ganguli I, Barnett ML. Trends in Outpatient Care Delivery and Telemedicine During the COVID-19 Pandemic in the US. JAMA Intern Med 2021 Mar 01;181(3):388-391. [doi: 10.1001/jamainternmed.2020.5928] [Medline: $\underline{33196765]}$

6. Hassan A, Mari Z, Gatto EM, Cardozo A, Youn J, Okubadejo N, International Telemedicine Study Group. Global Survey on Telemedicine Utilization for Movement Disorders During the COVID-19 Pandemic. Mov Disord 2020 Oct 24;35(10):1701-1711 [FREE Full text] [doi: 10.1002/mds.28284] [Medline: 32833273]

7. Verma S. Early Impact Of CMS Expansion Of Medicare Telehealth During COVID-19. Health Affairs Blog. 2020 Jul 15. URL: https://www.healthaffairs.org/do/10.1377/hblog20200715.454789/full [accessed 2021-06-01]

8. WHO Global Observatory for eHealth. Telemedicine: opportunities and developments in Member States: report on the second global survey on eHealth. Geneva, Switzerland: World Health Organization; 2010. URL: https://apps.who.int/iris/ handle/10665/44497

9. Myung S, McDonnell DD, Kazinets G, Seo HG, Moskowitz JM. Effects of Web- and computer-based smoking cessation programs: meta-analysis of randomized controlled trials. Arch Intern Med 2009 May 25;169(10):929-937. [doi: 10.1001/archinternmed.2009.109] [Medline: 19468084]

10. Barak A, Hen L, Boniel-Nissim M, Shapira N. A Comprehensive Review and a Meta-Analysis of the Effectiveness of Internet-Based Psychotherapeutic Interventions. Journal of Technology in Human Services 2008 Jul 03;26(2-4):109-160. [doi: 10.1080/15228830802094429]

11. Hyler SE, Gangure DP, Batchelder ST. Can telepsychiatry replace in-person psychiatric assessments? A review and meta-analysis of comparison studies. CNS Spectr 2005 May 07;10(5):403-413. [doi: 10.1017/s109285290002277x] [Medline: $15858458]$

12. Jin K, Khonsari S, Gallagher R, Gallagher P, Clark AM, Freedman B, et al. Telehealth interventions for the secondary prevention of coronary heart disease: A systematic review and meta-analysis. Eur J Cardiovasc Nurs 2019 Apr;18(4):260-271. [doi: $10.1177 / 1474515119826510]$ [Medline: 30667278 ]

13. Polisena J, Coyle D, Coyle K, McGill S. Home telehealth for chronic disease management: a systematic review and an analysis of economic evaluations. Int J Technol Assess Health Care 2009 Jul;25(3):339-349. [doi:

10.1017/S0266462309990201] [Medline: 19619353]

14. Batsis JA, DiMilia PR, Seo LM, Fortuna KL, Kennedy MA, Blunt HB, et al. Effectiveness of Ambulatory Telemedicine Care in Older Adults: A Systematic Review. J Am Geriatr Soc 2019 Aug;67(8):1737-1749 [FREE Full text] [doi: 10.1111/jgs.15959] [Medline: 31066916]

15. Timmermans S, Kaufman R. Technologies and Health Inequities. Annu. Rev. Sociol 2020 Jul 30;46(1):583-602. [doi: 10.1146/annurev-soc-121919-054802]

16. Internet/Broadband Fact Sheet. Pew Research Center. 2021. URL: https://www.pewresearch.org/internet/fact-sheet/ internet-broadband/ [accessed 2021-06-01]

17. Nishida T, Pick JB, Sarkar A. Japan s prefectural digital divide: A multivariate and spatial analysis. Telecommunications Policy 2014 Dec;38(11):992-1010. [doi: 10.1016/j.telpol.2014.05.004]

18. Lam K, Lu AD, Shi Y, Covinsky KE. Assessing Telemedicine Unreadiness Among Older Adults in the United States During the COVID-19 Pandemic. JAMA Intern Med 2020 Oct 01;180(10):1389-1391. [doi:

10.1001/jamainternmed.2020.2671] [Medline: 32744593]

19. Nouri S, Khoong E, Lyles C, Karliner L. Addressing equity in telemedicine for chronic disease management during the Covid-19 pandemic. NEJM Catalyst: Innovations in Care Delivery. 2020 May 04. URL: https://catalyst.nejm.org/doi/full/ 10.1056/CAT.20.0123 [accessed 2021-06-01]

20. Jaffe DH, Lee L, Huynh S, Haskell TP. Health Inequalities in the Use of Telehealth in the United States in the Lens of COVID-19. Popul Health Manag 2020 Oct;23(5):368-377. [doi: 10.1089/pop.2020.0186] [Medline: $\underline{32816644]}$

21. Rivera V, Aldridge MD, Ornstein K, Moody KA, Chun A. RESEARCHRacial and Socioeconomic Disparities in Access to Telehealth. J Am Geriatr Soc 2021 Jan;69(1):44-45. [doi: 10.1111/jgs.16904] [Medline: 33075143]

22. Pierce RP, Stevermer JJ. Disparities in use of telehealth at the onset of the COVID-19 public health emergency. J Telemed Telecare 2020 Oct 21:1357633X2096389. [doi: 10.1177/1357633x20963893]

23. Darrat I, Tam S, Boulis M, Williams AM. Socioeconomic Disparities in Patient Use of Telehealth During the Coronavirus Disease 2019 Surge. JAMA Otolaryngol Head Neck Surg 2021 Mar 01;147(3):287-295. [doi: 10.1001/jamaoto.2020.5161] [Medline: 33443539]

24. Ikeda N, Saito E, Kondo N, Inoue M, Ikeda S, Satoh T, et al. What has made the population of Japan healthy? The Lancet 2011 Sep;378(9796):1094-1105. [doi: 10.1016/s0140-6736(11)61055-6]

25. Market study on telemedicine. European Commission. 2018. URL: https://ec.europa.eu/health/sites/default/files/ehealth/ docs/2018 provision marketstudy telemedicine en.pdf [accessed 2021-06-05]

26. Ikeda T, Igarashi A, Odani S, Murakami M, Tabuchi T. Health-Related Quality of Life during COVID-19 Pandemic: Assessing Impacts of Job Loss and Financial Support Programs in Japan. Appl Res Qual Life 2021 Jan 30:1-17 [FREE Full text] [doi: 10.1007/s11482-021-09918-6] [Medline: $\underline{\text { 33552309] }}$ 
27. About Us. Rakuten Insight. URL: https://insight.rakuten.co.jp/en/aboutus.html [accessed 2021-06-01]

28. Tabuchi T, Kiyohara K, Hoshino T, Bekki K, Inaba Y, Kunugita N. Awareness and use of electronic cigarettes and heat-not-burn tobacco products in Japan. Addiction 2016 Apr;111(4):706-713. [doi: 10.1111/add.13231] [Medline: 26566956]

29. Tabuchi T, Gallus S, Shinozaki T, Nakaya T, Kunugita N, Colwell B. Heat-not-burn tobacco product use in Japan: its prevalence, predictors and perceived symptoms from exposure to secondhand heat-not-burn tobacco aerosol. Tob Control 2018 Jul;27(e1):e25-e33 [FREE Full text] [doi: 10.1136/tobaccocontrol-2017-053947] [Medline: 29248896]

30. Miyawaki A, Tabuchi T, Tomata Y, Tsugawa Y. Association between participation in the government subsidy programme for domestic travel and symptoms indicative of COVID-19 infection in Japan: cross-sectional study. BMJ Open 2021 Apr 13;11(4):e049069 [FREE Full text] [doi: 10.1136/bmjopen-2021-049069] [Medline: 33849861]

31. Gotanda H, Miyawaki A, Tabuchi T, Tsugawa Y. Association Between Trust in Government and Practice of Preventive Measures During the COVID-19 Pandemic in Japan. J Gen Intern Med 2021 Jun 22:1-7 [FREE Full text] [doi: 10.1007/s11606-021-06959-3] [Medline: 34159544]

32. International Standard Classification of Education: ISCED. Montreal, Quebec: UNESCO Institute for Statistics; 2012. URL: http://uis.unesco.org/sites/default/files/documents/international-standard-classification-of-education-isced-2011-en. pdf

33. Nakaya T, Honjo K, Hanibuchi T, Ikeda A, Iso H, Inoue M, Japan Public Health Center-based Prospective Study Group. Associations of all-cause mortality with census-based neighbourhood deprivation and population density in Japan: a multilevel survival analysis. PLoS One 2014;9(6):e97802 [FREE Full text] [doi: 10.1371/journal.pone.0097802] [Medline: 24905731]

34. Guidelines for the Appropriate Use of Telemedicine. Ministry of Health Labour and Welfare. 2019. URL: https://www. mhlw.go.jp/content/000534254.pdf [accessed 2021-06-08]

35. Belot M, Choi S, Jamison J, Papageorge N, Tripodi E, van den Broek-Altenburg E. Six-country survey on COVID-19. IZA - Institute of Labor Economics. 2020 May. URL: http://ftp.iza.org/dp13230.pdf [accessed 2021-06-01]

36. Mehta P, Braskett M, Tam JS, Espinoza J. Reimbursement patterns and user experiences in pediatric allergy home telehealth. Ann Allergy Asthma Immunol 2020 Dec;125(6):693-698.e1 [FREE Full text] [doi: 10.1016/j.anai.2020.06.003] [Medline: $\underline{32526378]}$

37. Schonlau M, van Soest A, Kapteyn A, Couper M. Selection Bias in Web Surveys and the Use of Propensity Scores. Sociological Methods \& Research 2009 Feb 01;37(3):291-318. [doi: 10.1177/0049124108327128]

38. Sentilhes L, Winer N, Azria E, Sénat M, Le Ray C, Vardon D, et al. Tranexamic Acid for the Prevention of Blood Loss after Vaginal Delivery. N Engl J Med 2018 Aug 23;379(8):731-742. [doi: 10.1056/nejmoa1800942]

39. Benjamini Y, Hochberg Y. Controlling the False Discovery Rate: A Practical and Powerful Approach to Multiple Testing. Journal of the Royal Statistical Society: Series B (Methodological) 2018 Dec 05;57(1):289-300. [doi: 10.1111/j.2517-6161.1995.tb02031.x]

40. Alexander GC, Tajanlangit M, Heyward J, Mansour O, Qato DM, Stafford RS. Use and Content of Primary Care Office-Based vs Telemedicine Care Visits During the COVID-19 Pandemic in the US. JAMA Netw Open 2020 Oct 01;3(10):e2021476 [FREE Full text] [doi: 10.1001/jamanetworkopen.2020.21476] [Medline: 33006622]

41. Patel SY, Mehrotra A, Huskamp HA, Uscher-Pines L, Ganguli I, Barnett ML. Variation In Telemedicine Use And Outpatient Care During The COVID-19 Pandemic In The United States. Health Aff (Millwood) 2021 Feb 01;40(2):349-358. [doi: 10.1377/hlthaff.2020.01786] [Medline: 33523745]

42. Ioannidis JPA. Infection fatality rate of COVID-19 inferred from seroprevalence data. Bull. World Health Organ 2020 Oct 14;99(1):19-33F. [doi: 10.2471/blt.20.265892]

43. Masso M. Determinants of employee work schedule and method control. Economic and Industrial Democracy 2012 Jul 09;34(3):451-469. [doi: 10.1177/0143831x12451348]

44. Summary of telemedicine use from July to September 2020. Ministry of Health Labour and Welfare. 2020. URL: https:/ /www.mhlw.go.jp/content/10803000/000690548.pdf [accessed 2021-06-01]

45. Eberly LA, Kallan MJ, Julien HM, Haynes N, Khatana SAM, Nathan AS, et al. Patient Characteristics Associated With Telemedicine Access for Primary and Specialty Ambulatory Care During the COVID-19 Pandemic. JAMA Netw Open 2020 Dec 01;3(12):e2031640 [FREE Full text] [doi: 10.1001/jamanetworkopen.2020.31640] [Medline: 33372974]

46. Kakani P, Sorensen A, Quinton JK, Han M, Ong MK, Kamdar N, et al. Patient Characteristics Associated with Telemedicine Use at a Large Academic Health System Before and After COVID-19. J Gen Intern Med 2021 Apr;36(4):1166-1168 [FREE Full text] [doi: 10.1007/s11606-020-06544-0] [Medline: $\underline{33506387]}$

47. Schweiberger K, Hoberman A, Iagnemma J, Schoemer P, Squire J, Taormina J, et al. Practice-Level Variation in Telemedicine Use in a Pediatric Primary Care Network During the COVID-19 Pandemic: Retrospective Analysis and Survey Study. J Med Internet Res 2020 Dec 18;22(12):e24345 [FREE Full text] [doi: 10.2196/24345] [Medline: 33290244]

\footnotetext{
Abbreviations

ICT: information and communications technology

IPW: inverse probability weighting
} 
ISCED: International Standard Classification of Education

JACSIS: Japan "COVID-19 and Society" Internet Survey

SES: socioeconomic status

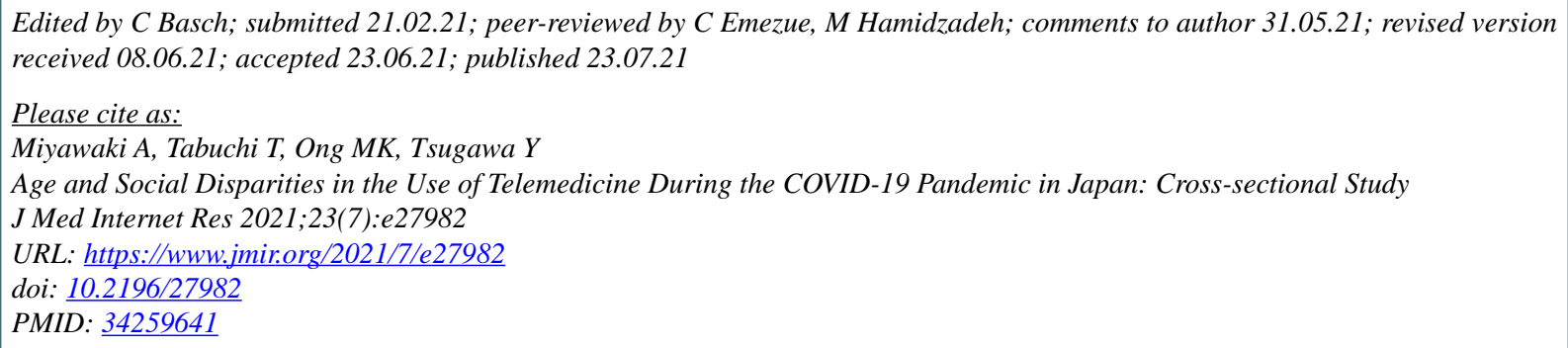

(C)Atsushi Miyawaki, Takahiro Tabuchi, Michael K Ong, Yusuke Tsugawa. Originally published in the Journal of Medical Internet Research (https://www.jmir.org), 23.07.2021. This is an open-access article distributed under the terms of the Creative Commons Attribution License (https://creativecommons.org/licenses/by/4.0/), which permits unrestricted use, distribution, and reproduction in any medium, provided the original work, first published in the Journal of Medical Internet Research, is properly cited. The complete bibliographic information, a link to the original publication on https://www.jmir.org/, as well as this copyright and license information must be included. 